\title{
Evaluation of breast cancer in women under 50 in a Mastology service in the Federal District, Brazil
}

\author{
Ana Cláudia Leite Vilela* (1), Lucimara Priscila Campos Veras ${ }^{1}$ (1), \\ Sérgio Eduardo Paiva Ramos ${ }^{1}$ (i), Sádia Martins de Paula Souza ${ }^{1}$ (i)
}

\section{ABSTRACT}

Introduction: Breast cancer is a relevant public health issue, and its incidence has increased in patients aged less than 50 years. This population usually receives a late diagnosis, which contributes with the poor prognosis of the condition. Objective: To assess the percentage of patients diagnosed with breast cancer before the age of 50 and compare them with the group that was diagnosed after the age of 50. Results: The general mean age was 54 years; $75.68 \%$ of the patients were younger than 50 years, aged between 40 and 49 years. Among the ones who were younger than 50, 35.14\% were in stage T4; 55.41\% underwent neoadjuvant chemotherapy; $16.22 \%$ presented distant metastasis; and $10.81 \%$, locoregional metastasis. On the other hand, among those aged more than $50,22.71 \%$ were in stage T4; 30.68\% underwent neoadjuvant chemotherapy; $11.36 \%$ presented distant metastasis; and 6.82\%, locoregional metastasis. Conclusion: Breast cancer in women aged less than 50 years in a Mastology service in the Federal District has been a matter of concern, for presenting more advanced tumors at the time of diagnosis; screening is still debatable.

KEYWORDS: breast neoplasms; mammography; mass screening; early cancer detection.

\section{INTRODUCTION}

Nowadays, breast cancer is a relevant public health problem. It is the most common malignant neoplasm among women in Brazil and in most of the world, after non-melanoma skin cancer. According to the last global statistics from the Global Cancer Observatory (GLOBOCAN), 2.1 million new cases of breast cancer and 627 thousand deaths caused by the disease have been estimated ${ }^{1}$. Breast cancer screening aims at detecting small asymptomatic tumors, thus contributing with the reduction of mortality. The ultrasound is limited to evaluate microcalcifications; therefore, it is not adequate for the screening of the general population ${ }^{2,3}$.

Mammography is the only test whose efficiency is proven for the reduction of breast cancer mortality ${ }^{4,5}$. The Ministry of Health recommends screening mammography for women without signs and symptoms of breast cancer, in the age group between 50 and 69 years, every two years ${ }^{6,7}$. This does not consider an important part of the population (women aged from 40 to 49 years), which responds for about $15 \%-20 \%$ of the breast cancer cases $^{8}$. The Brazilian Society of Mastology (SBM) recommends that breast cancer screening of women with usual population risk be performed through an annual mammography, including women aged from 40 to 75 years, aiming at the early diagnosis and the reduction of mortality ${ }^{1,8}$. After the age of 75 , screening mammography is recommended for women whose life expectancy is higher than seven years based on other comorbidities ${ }^{1,9,10}$.

Women aged more than 50 years are more prone to developing breast cancer; however, among young women, the clinical, pathological and immunohistochemical characteristics are more aggressive, staging is more advanced, tumor diameter is larger and there are more chances of developing metastasis ${ }^{11-13}$. Since breast cancer is considered as infrequent, younger women should be addressed special attention. A study from 2015 that aimed at understanding the experience of younger women diagnosed with breast cancer, who underwent a mastectomy, pointed out that systemic metastases can occur in $55.3 \%$ of the cases in these patients; on the other hand, for systemic metastasis in elderly women, the percentage is $39.2 \%$. The same study also showed that the mortality rate among younger women is $5 \%$ higher than among the elderly women ${ }^{14-16}$.

Based on the exposed, and considering that breast cancer is the most frequent type of cancer among women around the world, with high mortality rates, being a relevant public health issue, the main objective of this study was to assess the percentage of patients assisted in the Mastology service of Hospital Regional 
de Ceilândia, diagnosed with breast cancer before the age of 50 . Finally, it intends to provide subsidies so that public policies can be developed to favor a more efficient and earlier diagnosis, including the coverage and screening of younger women beyond specialized treatment, therefore increasing the chances of cure for these patients.

\section{METHOD}

This is a retrospective, cross-sectional, descriptive and observational study carried out to assess the percentage of breast cancer in women, aged less than 50 years, assisted at the Mastology service of Hospital Regional da Ceilândia, from January 2015 to April 2020. The data were collected from the charts of the selected patients, inserted in Excel spreadsheets and statistically evaluated by the Statistical Package for the Social Sciences (SPSS), version 25 . Significance level was $\mathrm{p} \leq 0.05$. Both the Student's t-test and the $\chi^{2}$ test were used. This analysis was approved by the Research Ethics Committee, CAAE: 35587420.3.0000.8101.

\section{RESULTS}

Our study included 162 patients who met the inclusion criteria, of which $45.70 \%$ were younger than 50 years. The general mean age was $54 \pm 13.11$; the mean of patients younger than 50 years was 42.6 \pm 5 , and the mean of patients aged 50 years or more was $63.3 \pm 9.5$.

Of the included patients, $9.80 \%$ had family history of breast or ovarian cancer; $84.57 \%$ had normal menarche (8-16 years of age); $75.93 \%$ were multiparous. For $32.10 \%$, the diagnosed histological type was luminal-B invasive ductal carcinoma (IDC); for $22.22 \%$, it was luminal-A IDC; and for $14.20 \%$, it was triple negative IDC. In $34.57 \%$ of the patients, the initial tumor size was T2 (> 2 and $\leq 5 \mathrm{~cm})$; in $28.40 \%$, it was T4; and in $20,99 \%$, it was T3 $(>5 \mathrm{~cm})$. Axillary impairment at physical examination was observed in $38.27 \%$ of the patients. For $59.26 \%$ of them, a core needle biopsy was performed. Axillary dissection was performed in $50 \%$ of them. Neoadjuvant chemotherapy (CT) was performed in $41.98 \%$ of the patients, and $37.65 \%$ underwent adjuvant CT; $11.11 \%$ obtained complete post-neoadjuvant CT response, and $37.65 \%$ had partial response. Distant metastasis was observed in $13.58 \%$ of the patients, and locoregional metastasis, in $8.64 \%$.

By correlating the patients aged less than 50 years and those aged 50 years or older, we observed that $8.11 \%$ of the former had family history of breast/ovarian cancer; $83.7 \%$ had normal menarche (8-16 years of age); and $70.27 \%$ were multiparous. Of the patients aged 50 years or older, $11.36 \%$ had family history of breast/ovarian cancer; $85.23 \%$ had normal menarche (8-16 years of age); and $75.93 \%$ were multiparous (Table 1 ).

Patients aged less than 50 years were prevalent in the age group between 40 and 49 years $(75.68 \%)$. The histological type luminal-B IDC was diagnosed in $33.68 \%$ of the patients; luminalA IDC, in $20.27 \%$; and triple negative IDC, in $16.22 \%$. The initial tumor size was T4 for $35.14 \%$ of them; T2, for $27.03 \%$ of them; and T3, for $27.03 \%$ of them. Of the patients aged more than 50 years, $30.68 \%$ were diagnosed with histological type luminal-B IDC; $23.86 \%$, with luminal-A IDC; and $12.50 \%$, with triple negative IDC. The initial tumor size was T2 in $40.91 \%$ of them; T4, in $22.73 \%$; and T1, in $20.45 \%$ (Table 2).

Table 1. Epidemiological characteristics of women assisted for breast cancer treatment from January, 2015, to April, 2020.

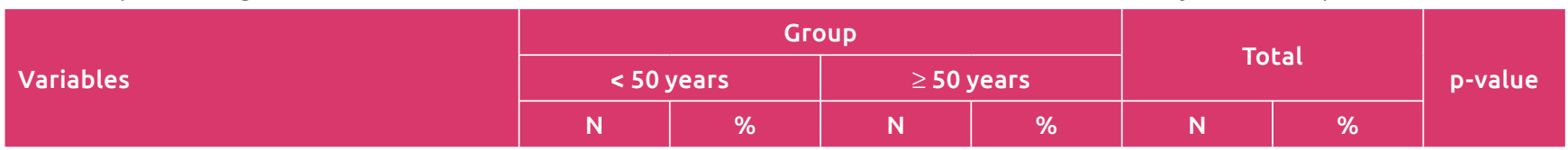

Family history of breast/ovarian cancer

\begin{tabular}{|c|c|c|c|c|c|c|c|}
\hline Yes (breast/ovarian) & 6 & 8.11 & 10 & 11.36 & 16 & 9.88 & \multirow{3}{*}{0.36} \\
\hline No & 67 & 90.54 & 78 & 88.64 & 145 & 89.51 & \\
\hline Not informed & 1 & 1.35 & 0 & 0.00 & 1 & 0.62 & \\
\hline \multicolumn{8}{|l|}{ Menarcche } \\
\hline Not informed & 11 & 14.86 & 10 & 11.36 & 21 & 12.96 & \multirow{4}{*}{0.132} \\
\hline Normal (8-16 years of age) & 62 & 83.78 & 75 & 85.23 & 137 & 84.57 & \\
\hline Early (< 8 years of age) & 1 & 1.35 & 0 & 0.00 & 1 & 0.62 & \\
\hline Late (> 16 years of age) & 0 & 0.00 & 3 & 3.41 & 3 & 1.85 & \\
\hline
\end{tabular}

Parity

\begin{tabular}{l|c|c|c|c|c|c|c|c|}
\hline Nulliparous & 11 & 14.86 & 6 & 6.82 & 17 & 10.49 & \multicolumn{1}{c}{0} \\
\hline Primiparous & 10 & 13.51 & 6 & 6.82 & 16 & 9.88 \\
\hline Multiparous & 52 & 70.27 & 71 & 80.68 & 123 & 75.93 \\
\hline Not informed & 1 & 1.35 & 5 & 5.68 & 6 & 3.70 & \\
\hline
\end{tabular}


Of the patients aged less than 50 years, $41.89 \%$ presented with axillary impairment at physical examination. Sentinel lymph node biopsy was performed in $60.23 \%$ of them, and $44.32 \%$ underwent axillary dissection (Table 3).

Of the patients aged less than 50 years, $55.41 \%$ underwent neoadjuvant CT, and $35.14 \%$ underwent adjuvant CT. There was partial post-neoadjuvant CT response in $47.30 \%$ of them, and complete response in $14.86 \%$. Of the patients aged 50 years or older, $30.68 \%$ underwent neoadjuvant CT, and $37.65 \%$ were submitted to adjuvant CT. There was partial post-neoadjuvant $\mathrm{CT}$ response in $37.64 \%$ of them, and complete response in $11.11 \%$ (Table 4).

Distant metastasis was observed in $16.22 \%$, and locoregional metastasis, in $10.81 \%$ of the patients aged less than 50 years. Of those aged 50 years or more, $11.36 \%$ presented with distant metastasis, and $6.82 \%$, with locoregional metastasis (Table 5).

\section{DISCUSSION}

Family history of breast or ovarian cancer was observed in 3.7\% of the patients aged less than 50 years. In relation to those aged more than 50 years, these presented $8.05 \%$ more nulliparity and $3.72 \%$ more triple negative IDC results; also, $12.41 \%$ more initial tumor sizes T4, and $11.12 \%$ more initial sizes T3. Younger patients are diagnosed with initial tumor size above $\mathrm{T} 3$, which contributes with a poor prognosis. There was axillary impairment (at physical examination) in $6.7 \%$ more patients than among those aged more than 50 ; however, the percentage of $6.76 \%$ more axillary dissection procedures was observed among patients aged less than 50 . The frequency of neoadjuvant $\mathrm{CT}$ was higher than $24.72 \%$ among patients aged less than 50 years, who also presented $17.75 \%$ more partial post-neoadjuvant CT response and 6.91\% more complete response.

In a study carried out by Franzoi et al. ${ }^{17}$, the authors identified that $17 \%$ of the patients with breast cancer were aged less

Table 2. Clinial and pathological characteristics of patients assisted at Hospital Regional da Ceilândia from January 2015 to April 2020.

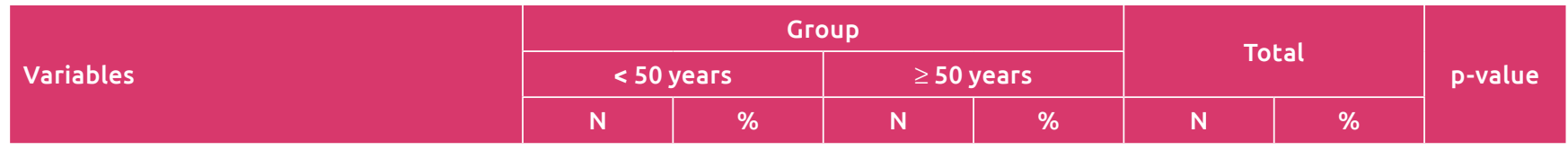

Age group (years old)

\begin{tabular}{|c|c|c|c|c|c|c|c|}
\hline$<30$ & 1 & 1.35 & 0 & 0.00 & 1 & 0.62 & \multirow{3}{*}{0,002} \\
\hline $30-39$ & 17 & 22.97 & 0 & 0.00 & 17 & 10.49 & \\
\hline $40-49$ & 56 & 75.68 & 0 & 0.00 & 56 & 34.57 & \\
\hline$\geq 50$ & 0 & 0.00 & 88 & 100.00 & 88 & 54.32 & \\
\hline
\end{tabular}

Histological type

\begin{tabular}{|c|c|c|c|c|c|c|c|}
\hline HER-2 luminal B IDC & 5 & 6.76 & 5 & 5.68 & 10 & 6.17 & \multirow{13}{*}{0,656} \\
\hline HER-2 OVEREXPRESSION IDC & 4 & 5.41 & 10 & 11.36 & 14 & 8.64 & \\
\hline Luminal-A IDC & 15 & 20.27 & 21 & 23.86 & 36 & 22.22 & \\
\hline Luminal-B IDC & 25 & 33.78 & 27 & 30.68 & 52 & 32.10 & \\
\hline Luminal HER-2 IDC & 4 & 5.41 & 4 & 4.55 & 8 & 4.94 & \\
\hline Triple negative IDC & 12 & 16.22 & 11 & 12.50 & 23 & 14.20 & \\
\hline CDIS HER 2 SUPEREXPRESSO & 1 & 1.35 & 0 & 0.00 & 1 & 0.62 & \\
\hline Luminal-A ISDC & 1 & 1.35 & 0 & 0.00 & 1 & 0.62 & \\
\hline Luminal-B ISDC & 1 & 1.35 & 2 & 2.27 & 3 & 1.85 & \\
\hline Luminal A ILC & 1 & 1.35 & 2 & 2.27 & 3 & 1.85 & \\
\hline Luminal B ILC & 1 & 1.35 & 4 & 4.55 & 5 & 3.09 & \\
\hline Triple negative ILC & 1 & 1.35 & 0 & 0.00 & 1 & 0.62 & \\
\hline Others & 3 & 4.05 & 2 & 2.27 & 5 & 3.09 & \\
\hline \multicolumn{8}{|l|}{ Initial tumor size } \\
\hline $\mathrm{T} 1 \leq 2 \mathrm{~cm}$ & 8 & 10.81 & 18 & 20.45 & 26 & 16.05 & \multirow{4}{*}{0,026} \\
\hline $\mathrm{T} 2>2$ and $\leq 5 \mathrm{~cm}$ & 20 & 27.03 & 36 & 40.91 & 56 & 34.57 & \\
\hline $\mathrm{T} 3>5 \mathrm{~cm}$ & 20 & 27.03 & 14 & 15.91 & 34 & 20.99 & \\
\hline T4 & 26 & 35.14 & 20 & 22.73 & 46 & 28.40 & \\
\hline
\end{tabular}

T: size. ISDC: In situ ductal carcinoma; IDC: invasive ductal carcinoma; ILC: infiltrating lobular carcinoma. 
than 50 years. In our study, the frequency of patients aged less than 50 years with breast cancer was lower; however, the findings of the authors corroborate ours regarding the fact that younger patients are more symptomatic at diagnosis, often presenting stage III, T3/T4, grade 3, HER-2 positive, luminal-B and triple negative cancer subtypes.

In a study carried out by Laila et al. ${ }^{18}$ including 349 women aged between 24 and 90 years, the authors observed that $8.3 \%$

Table 3. Axillary status of women with breast cancer from January 2015 to April 2020.

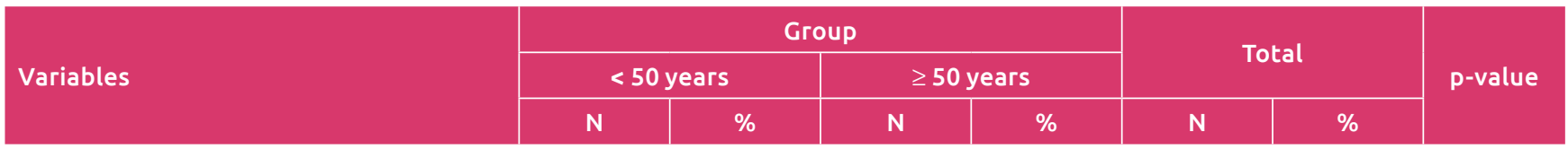

Axillary impairment (at physical examination)

\begin{tabular}{|c|c|c|c|c|c|c|c|}
\hline Yes & 31 & 41.89 & 31 & 35.23 & 62 & 38.27 & \multirow{2}{*}{0.385} \\
\hline No & 43 & 58.11 & 57 & 64.77 & 100 & 61.73 & \\
\hline \multicolumn{8}{|c|}{ Sentinel lymph node biopsy } \\
\hline Yes & 30 & 40.54 & 53 & 60.23 & 83 & 51.23 & \multirow{3}{*}{0.060} \\
\hline No & 43 & 58.11 & 33 & 37.50 & 76 & 46.91 & \\
\hline Not informed & 1 & 1.35 & 2 & 2.27 & 3 & 1.85 & \\
\hline \multicolumn{8}{|l|}{ Axillary dissection } \\
\hline Yes & 42 & 56.76 & 39 & 44.32 & 81 & 50.00 & \multirow{3}{*}{0.274} \\
\hline No & 31 & 41.89 & 48 & 54.55 & 79 & 48.77 & \\
\hline Not informed & 1 & 1.35 & 1 & 1.14 & 2 & 1.23 & \\
\hline
\end{tabular}

Table 4. Systemic treatment of women with breast cancer from Janaury 2015 to April 2020.

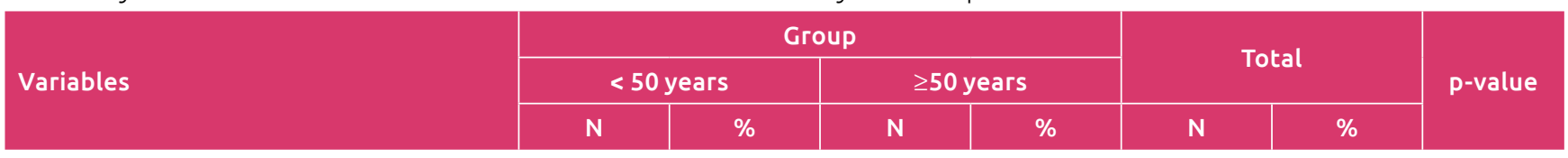

Neoadjuvant CT

\begin{tabular}{|c|c|c|c|c|c|c|c|}
\hline Yes & 41 & 55.41 & 27 & 30.68 & 68 & 41.98 & \multirow{2}{*}{0.002} \\
\hline No & 33 & 44.59 & 61 & 69.32 & 94 & 58.02 & \\
\hline \multicolumn{8}{|l|}{ Adjuvant CT } \\
\hline Yes & 26 & 35.14 & 35 & 39.77 & 61 & 37.65 & \multirow{2}{*}{0.544} \\
\hline No & 48 & 64.86 & 53 & 60.23 & 101 & 62.35 & \\
\hline \multicolumn{8}{|l|}{ Post-neo CT response } \\
\hline Complete & 11 & 14.86 & 7 & 7.95 & 18 & 11.11 & \multirow{4}{*}{0.013} \\
\hline Partial & 35 & 47.30 & 26 & 29.55 & 61 & 37.65 & \\
\hline Did not undergo it & 28 & 37.84 & 54 & 61.36 & 82 & 50.62 & \\
\hline Total & 0 & 0.00 & 1 & 1.14 & 1 & 0.62 & \\
\hline
\end{tabular}

Neo CT: neoadjuvant chemotherapy; CT: chemotherapy.

Table 5. Characterization of the presence of metastasis in women with breast cancer from January 2015 to April 2020.

\begin{tabular}{|c|c|c|c|c|c|c|c|}
\hline \multirow{3}{*}{ Variables } & \multicolumn{4}{|c|}{ Group } & \multirow{2}{*}{\multicolumn{2}{|c|}{ Total }} & \multirow{3}{*}{ p-value } \\
\hline & \multicolumn{2}{|c|}{$<50$ years } & \multicolumn{2}{|c|}{$\geq 50$ years } & & & \\
\hline & $\mathbf{N}$ & $\%$ & $\mathbf{N}$ & $\%$ & $\mathbf{N}$ & $\%$ & \\
\hline \multicolumn{8}{|l|}{ Metastasis } \\
\hline Yes/distant & 12 & 16.22 & 10 & 11.36 & 22 & 13.58 & \multirow{3}{*}{0.106} \\
\hline Yes/locoregional & 8 & 10.81 & 6 & 6.82 & 14 & 8.64 & \\
\hline No & 54 & 72.97 & 72 & 81.82 & 126 & 77.78 & \\
\hline
\end{tabular}


were aged less than 40 years, and most were diagnosed at early stages; invasive ductal carcinoma was the most common type regarding immunohistochemical characteristics. Most cancers were smaller than $2 \mathrm{~cm}$. In our study, the findings were different: patients aged less than 40 years represented $11.1 \%$ of the sample, and less than 50 years, $45.7 \%$. The prevalence of tumor sizes was between 2 and $5 \mathrm{~cm}$, however, in patients aged less than 50 years, they were larger than $5 \mathrm{~cm}$. The prevalent histological type, regardless of age, was luminal-B IDC.

Pereira et al..$^{19}$ observed that the age group of 35 to 40 years was the most affected one. In our study, it was 40 to 49 years of age. In an analysis carried out by Magalhães et al. ${ }^{20}$, distant metastasis was observed in $3.1 \%$ of the sample, and locoregional metastasis, in $0.6 \%$, corroborating the findings of our study, in which distant metastasis was found in $13.58 \%$ of the patients, and rates of $4.8 \%$ more chances of this type of metastasis in patients aged less than 50 , and $4 \%$ among patients with locoregional metastasis.

\section{CONCLUSION}

Considering the presented study, we can conclude that breast cancer in women aged less than 50 years in a Mastology service of the Federal District has been a reason of concern among these patients, since they present with more advanced tumors at diagnosis, more need for neoadjuvant $\mathrm{CT}$ and higher occurrence of metastasis, which reinforces the hypothesis that the reduction in late diagnosis may increase the chances of cure. The highest prevalence among those aged less than 50 years was in the age group of 40 to 49 years, which brings up more discussions about the need for screening.

The review of the official current recommendations of the Ministry of Health for the beginning of breast cancer screening should be a base for public health policies, in order to recruit young women and generate higher rates of diagnosis, better care for the patient and the possibility of an earlier treatment for the disease.

It is important to mention that the lack of access of the population to health also leads to a later diagnosis, and this fact illustrates the urgency for improvements in public health, from the approach of the patient in primary care, providing access to information, until the proper referral to a tertiary service in search for better health indicators.

\section{AUTHORS' CONTRIBUTIONS}

A.C.L.V.: Concept, Visualization, Writing - original draft.

L.V.: Project administration, Supervision, Writing - review \& editing.

S.P.R.: Data curation, Formal Analysis, Software, Supervision.

S.M.: Investigation, Methodology.

\section{REFERENCES}

1. Organização Mundial da Saúde. Globocan 2020 (Breast). The Global Cancer Observatory. Organização Mundial da Saúde; 2020.

2. Urban LAB, Chala LF, Bauab SP, Schaefer MB, Santos RP, Maranhão NMA, et al. Recomendações do Colégio Brasileiro de Radiologia e Diagnóstico por Imagem, da Sociedade Brasileira de Mastologia e da Federação Brasileira das Associações de Ginecologia e Obstetrícia para rastreamento do câncer de mama por métodos de imagem. Radiol Bras. 2017;50(4):244-9. http://dx.doi. org/10.1590/0100-3984.2017-0069

3. Dias ADA, Mauro MN, Puy TC, Oliveira CM, Fecury AA, Dias CAGM, et al. Atualização sobre os principais aspectos relacionados ao câncer de mama. Rev Cient Multidiscipl Núcleo Conhecim. 2017;8(11):5-17. http://dx.doi.org/10.32749/ nucleodoconhecimento.com.br/saude/cancer-de-mama

4. Instituto Nacional de Câncer. Detecção precoce do câncer de mama. Brasil: Instituto Nacional de Câncer, Ministério da Saúde; 2020.

5. Instituto Nacional de Câncer. Confira as recomendações do Ministério da Saúde para o rastreamento do câncer de mama. Instituto Nacional de Câncer, Ministério da Saúde; 2019.
6. Instituto Nacional de Câncer. Fatores de risco para o câncer de mama. Instituto Nacional de Câncer, Ministério da Saúde; 2019.

7. Instituto Nacional de Câncer. Estatísticas de câncer. Instituto Nacional de Câncer, Ministério da Saúde; 2020.

8. Sociedade Brasileira de Mastologia. Sociedades brasileiras recomendam mamografia a partir dos 40 anos. Sociedade Brasileira de Mastologia; 2021.

9. Migowski A, Silva GA, Dias MBK, Diz MPE, Sant'Ana DR, Nadanovsky P. Diretrizes para detecção precoce do câncer de mama no Brasil. II - Novas recomendações nacionais, principais evidências e controvérsias. Cad Saúde Pública. 2018;34(6):1-16. https://doi.org/10.1590/0102$311 \times 00074817$

10. Figueiredo MB, Silva DND, Costa MCSD. Câncer de mama em mulheres com idade inferior a 40 anos em Rio Branco-Acre: percepção e aceitação. DêCiência em Foco. 2020;4(1):29-44.

11. Dutra MC, Rezende MA, Andrade VP, Soares FA, Ribeiro MV, Paula EC, et al. Imunofenótipo e evolução de câncer de mama: comparação entre mulheres muito jovens e mulheres na pósmenopausa. Rev Bras Ginecol Obstet. 2009;31(2):54-60. https:// doi.org/10.1590/S0100-72032009000200002 
12. Monteiro DLM, Nunes CL, Rodrigues NCP, Antunes CA, Almeida EM, Barmpas DBS, et al. Fatores associados ao câncer de mama gestacional: estudo caso-controle. Ciênc Saúde Colet. 2019;24(6):2361-9. https://doi.org/10.1590/141381232018245.18392017

13. Cardoso MDPC. Associação entre câncer de mama e uso de contraceptivos orais de mulheres em idade fértil [thesis]. Fortaleza: Universidade Federal do Ceará; 2020.

14. Silva DA, Silva LK, Fonseca CSM. Câncer de mama em mulheres jovens: uma avaliação do perfil clínico-epidemiológico e molecular em um centro de tratamento especializado. Braz J Health Rev. 2019;2(6):6076-87. https://doi.org/10.34119/ bjhrv2n6-102

15. Almeida TGD, Comassetto I, Alves KMC, Santos AAP, Silva JMO, Trezza MCSF. Vivência da mulher jovem com câncer de mama e mastectomizada. Esc Anna Nery. 2015;19(3):432-8. https://doi.org/10.5935/1414-8145.20150057

16. Lemos NADF, Freitas-Júnior R, Moreira MAR, Silva TC, Oliveira JC, Silva CMB. Difficulties in collecting data on ductal carcinoma in situ at a population-based cancer registry.
Mastology. 2019;29(2):86-9. https://doi.org/10.29289/25945394 20190000421

17. Franzoi MA, Rosa DD, Zaffaroni F, Werutsky G, Simon S, Bines J, et al. Advanced stage at diagnosis and worse clinicopathologic features in young women with breast cancer in brazil: a subanalysis of the AMAZONA III Study (GBECAM 0115). J Glob Oncol. 2019;5:1-10. https://doi.org/10.1200/jgo.19.00263

18. Laila HJEA, Zenkner JRG, Araújo MC, Becker JDL, Pereira AD. Characterization of prognostic factors of breast cancer among women with this condition attended by the Brazilian unified health system in the municipality of Bagé, Rio Grande do Sul, Brazil. Mastology. 2019;29(2):64-70. https://doi.org/10.29289/2 594539420190000438

19. Pereira HFB, Nunes GPS, Viapiana PS, Silva KLT. Profile of care in young women with breast cancer in Amazonas: 11 years study. Mastology. 2019;29(1):20-4. https://doi.org/10.29289/25 94539420190000426

20. Magalhães GDF, Cavalcanti FP, Lima MVA, Castro RB. Evaluation of local recurrence of breast conservation surgery at the Ceará institute of cancer. Mastology. 2019;29(1):10-3. https://doi.org/10.29289/2594539420190000371 